\title{
PERCEPCIONES SOBRE COMPORTAMIENTOS SEXUALES DE RIESGO EN PERSONAS QUE VIVEN CON VIH/SIDA Y RECIBEN TRATAMIENTO ANTIRRETROVIRAL EN PIURA, PERÚ*
}

\author{
José P. Juarez-Vílchez ${ }^{1, a}$, Edwar J. Pozo 1,b
}

\begin{abstract}
RESUMEN
Objetivo. Explorar y describir experiencias y motivaciones de las personas que viven con VIH (PVVS) y reciben tratamiento antirretroviral de gran actividad (TARGA), para tener comportamientos sexuales de riesgo para transmisión del $\mathrm{VIH}$, en dos hospitales públicos de Piura. Materiales y métodos. Estudio cualitativo basado en entrevistas en profundidad y grupos focales en 40 PVVS, de 15 a 39 años de edad, cuyo análisis se realizó bajo el enfoque de la "teoría fundamentada", se realizó un análisis por categorías, se usó el software ATLAS. Ti Versión 5.0. Resultados. Las PVVS que reciben TARGA tienen comportamientos sexuales de riesgo. Esto concuerda con estudios cuantitativos-epidemiológicos que afirman que el inicio de la era TARGA está relacionada con continuación o incremento de comportamientos sexuales de riesgo. Conclusiones. Las PVVS al recibir antirretrovirales y mejorar el estado de su salud, mantienen comportamientos sexuales de riesgo que podrían facilitar la transmisión del virus a sus parejas serodiscordantes e incrementar el número de casos con esta infección. Hasta el momento, las actividades de prevención se han dirigido mayormente hacia personas que se supone no están infectadas, no obstante, se requiere también de un trabajo intenso de prevención secundaria, que incluya explícitamente el abordaje de la sexualidad en todas sus dimensiones.
\end{abstract}

Palabras clave: SIDA; VIH; Agentes antirretrovirales; Conducta sexual; Sexo inseguro; Investigación cualitativa (fuente: DeCS BIREME).

\section{RISK SEXUAL BEHAVIOR AMONG PEOPLE LIVING WITH HIVIAIDS AND RECEIVING ANTIRETROVIRAL THERAPY IN PIURA, PERU}

\begin{abstract}
Objetive. To explore opinions and beliefs about risky sexual behavior and $\mathrm{HIH}$ transmission in tow hospital of Piura. Material y methods. Qualitative study based on extensive interviews and focus groups of people over 15 years old of age living with HIV. Interviews were recorded as audio, and then transcribed as text in MS Word. Information was analyzed with AtlasTi. Results. Results indicate that people living with HIV and receive antiretrovirals practice risky sexual behavior. Those results agree with quantitative-epidemiological studies establishing that TARGA era is associated with continuation or increase of risky sexual behavior. Two reasons could explain such behavior; first there is a belief that HIV is innocuous by effect of the antiretrovirals. Second, there is belief that a medical confirmation of undetectable viral count means being healed from infection. Conclusions. People living with HIV receiving antiretrovirals improving general health status maintain risky sexual behavior that may facilitate HIV transmission to their serodiscordant partners and increase the number of people infected. Until now, prevention activities mostly targeted people believed not to be infected, however, it is also necessary an intense secondary prevention effort that includes an explicit approach of sexuality in its entire dimension.
\end{abstract}

Key words: AIDS; HIV; Anti-retroviral agents; Sexual behavior; Unsafe sex; Qualitative research (source: MeSH NLM).

\section{INTRODUCCIÓN}

En el Perú y en el mundo, la infección por el virus de la inmunodeficiencia humana $(\mathrm{VIH})$ y el síndrome de inmunodeficiencia adquirida (SIDA) continúa siendo un problema de salud pública de alta importancia. El Programa Conjunto de las Naciones Unidas sobre $\mathrm{VIH}$ SIDA (ONUSIDA) en el 2008, estimó que había 33,4 millones [31,1 a 35,8 millones] de personas que viven con el VIH en todo el mundo ${ }^{(1)}$.
No obstante, las intervenciones para el tratamiento de las personas afectadas han evolucionado desde el manejo de infecciones oportunistas hasta la reducción de la replicación viral, es allí donde la terapia antirretroviral de gran actividad (TARGA) cumple un papel relevante; transformando la epidemiología del $\mathrm{VIH}$ al modificar favorablemente su historia natural, al retrasar la progresión de la enfermedad (2) y permitir que las personas que viven con este virus (PVVS) lleguen a tener estilos de vida similares a los una persona no

\footnotetext{
Subregión de Salud "Luciano Castillo Colonna" Sullana, Perú.

a Licenciado en Obstetricia, Candidato a Magister en Género, Sexualidad y Salud Reproductiva;

b Biólogo-Microbiólogo, Candidato a Magister en Control de Enfermedades Infecciosas y Tropicales.

* El resumen de esta investigación fue presentado en el V Foro Latinoamericano y del Caribe en VIH/SIDA e ITS, realizado del 21 al 23 de noviembre en Lima, Perú.
}

Recibido: 03-08-09 Aprobado: 03-03-10 
infectada. Desde el año 2004, el Ministerio de Salud de Perú (MINSA), administra esta terapia en forma gratuita a más de diez mil personas afectadas, con un incremento anual importante del número de beneficiados. La región Piura tiene aproximadamente 300 personas adultas que reciben este tipo de tratamientos.

Se reconoce que la transmisión del VIH es favorecida por conductas sexuales de riesgo - relaciones sexuales (RS) sin protección, RS con trabajadoras sexuales o múltiples parejas sexuales - que estas personas mantienen (3-6), pudiéndose afirmar que la TARGA y los comportamientos sexuales de riesgo estarían vinculados de alguna manera, sustentado en que al mejorar la calidad de vida y al sentirse mejor física y emocionalmente, puede simultáneamente, producirse un incremento de los comportamientos sexuales de riesgo ${ }^{(5,7,8)}$.

Estudios en hombres que tienen sexo con otros hombres $(\mathrm{HSH})$ realizados en Europa y América del Norte informan que al iniciar TARGA, se presenta reducción de la carga viral a niveles indetectables y alivio de los síntomas; pero también hay retorno a comportamientos sexuales riesgosos ${ }^{(9,10)}$ esto es atribuible a dos aspectos; en primer lugar, a los beneficios físicos, sociales y emocionales; y en segundo lugar al optimismo, porque las consecuencias de la infección son menos trágicas que en el pasado ${ }^{(11)}$.

En un metaanálisis del año $2004^{(12)}$ se informó que la prevalencia de RS sin protección no fue significativamente mayor en el grupo de personas con infección por VIH recibiendo TARGA, que en aquellas con carga viral indetectable. No obstante, las relaciones sexuales sin protección se asociaron con las creencias de la gente sobre la carga viral y TARGA. Por otro lado, un estudio francés del año $2002{ }^{(6)}$ informó que las personas que se involucraban en RS de riesgo, no diferían en términos de carga viral en plasma, lo que sugiere, a juicio de los autores, que el hecho de que el paciente conozca su respuesta (buena o mala) al TARGA, no es determinante para dejar las prácticas sexuales seguras.

Considerando que algunos estudios advierten que se están incrementando las infecciones de transmisión sexual (ITS) en personas que viven con $\mathrm{VIH}$ por que tienen relaciones sexuales no protegidas, con la consiguiente diseminación de virus mutantes, asimismo, investigaciones que informan que no concuerdan con esos hallazgos; sumado a ello, el creciente optimismo suscitado por los nuevos tratamientos antirretrovirales que mejoran notablemente la calidad de vida de las PVVS, podría existir influencia en el hecho que se aumente o disminuya la preocupación en tener comportamientos sexuales seguros, por ello, el objetivo de este estudio fue explorar opiniones y creencias sobre el comportamiento sexual de riesgo y la transmisión del VIH en un grupo de pacientes que está recibiendo TARGA.

\section{MATERIALES Y MÉTODOS}

\section{DISEÑO DEL ESTUDIO}

Investigación cualitativa, diseñada con una perspectiva exploratoria y descriptiva apoyada en el construccionismo social o socioconstruccionismo, considerando que las personas participan activamente en la creación de sus percepciones sociales sobre el ejercicio de su sexualidad, tratando de encontrar explicaciones sobre las relaciones sexuales de riesgo. Se registró información mediante dos técnicas:

a. Entrevistas en profundidad, con el fin de obtener información directa de lo que las personas sienten o piensan respecto de sus comportamientos sexuales, para tratar de descifrar la perspectiva de las y los entrevistados a través de su relato y en su propio universo lingüístico.

b. Grupos focales, que nos permitió el acceso a los consensos y disensos sobre los significados compartidos social y culturalmente por los participantes, y que fueron recreados en el contexto de la interacción propia de esta técnica; nos permitió acceder a los aspectos más sociales de la construcción de sus percepciones y los campos de significado.

\section{PARTICIPANTES}

El estudio se realizó en la región Piura, ubicada al norte de Perú, en dos Hospitales del MINSA que brindan TARGA: Hospital Santa Rosa de la ciudad de Piura y Hospital de Apoyo III de la ciudad de Sullana. Los participantes fueron personas que viven con VIH, comprendidas entre 15 y 39 años de edad, cuyas características sociodemográficas se detallan en la Tabla 1.

Participaron 40 personas seleccionadas por conveniencia, de las cuales 32 participaron de cuatro grupos focales, clasificados de acuerdo con su sexo (masculino, femenino) y tiempo que vienen recibiendo TARGA (entre seis y 12 meses; y más de 12 meses); se asume que las personas que tienen más de un año en tratamiento poseen un conocimiento más firme de lo que implica tener la infección y los cuidados que se deben adoptar en los coitos; situación que sería menos frecuente en una persona que tiene menos de seis meses en tratamiento. Ocho personas participaron en las entrevistas en profundidad. 
Tabla 1. Características sociodemográficas de los participantes

\begin{tabular}{|c|c|}
\hline Característica & Participantes \\
\hline \multicolumn{2}{|l|}{ Edad } \\
\hline 15 - 19 años & 2 \\
\hline $20-24$ años & 5 \\
\hline $25-29$ años & 15 \\
\hline $30-34$ años & 10 \\
\hline 35 - 39 años & 8 \\
\hline \multicolumn{2}{|l|}{ Estado civil } \\
\hline Casada/o & 7 \\
\hline Conviviente & 13 \\
\hline Soltera & 11 \\
\hline Separada/o - viuda/o & 9 \\
\hline \multicolumn{2}{|l|}{ Educación } \\
\hline Menos de 7 años & 10 \\
\hline Entre 7 y 12 años & 22 \\
\hline 12 años a más & 8 \\
\hline
\end{tabular}

\section{INSTRUMENTOS}

Se usó una guía para las entrevistas en profundidad y otra para los grupos focales. Ambos instrumentos fueron previamente validados con la población objetivo y aplicados por entrevistadores capacitados.

\section{PROCEDIMIENTOS}

Los participantes fueron seleccionados y contactados por el personal de salud responsable de brindar el tratamiento antirretroviral de los dos hospitales, al momento que acudían a recibir sus medicamentos siempre y cuando cumplieran los criterios de inclusión. Se les explicaba la investigación y sus objetivos, la forma de su participación y en caso de aceptación se procedía a leerles el consentimiento informado y, de acuerdo con su decisión, procedían a firmarlo; posteriormente se coordinó el día, hora y lugar de la entrevista y del grupo focal, que en promedio fue de una hora y dos horas, respectivamente.

\section{ASPECTOS ÉTICOS}

El protocolo de investigación fue revisado y aprobado por el comité de ética del Hospital Nacional Dos de Mayo en la ciudad de Lima. La participación tuvo carácter voluntario, anónimo, confidencial y previo consentimiento informado por escrito. Se buscó que la aceptación no sea pasiva por parte de las personas, sino que sea una participación sin coerción de ningún tipo, con posibilidad de retiro voluntario. Participó un adolescente de 15 años y uno de 19 años, ambos contaron con autorización de sus padres, además del asentimiento informado.

Las transcripciones fueron codificadas para mantener el anonimato y guardadas bajo llave. Luego de concluida la investigación se realizó dos reuniones con los participantes, autoridades y personas interesadas a fin de presentar los resultados, en un proceso participativo y democrático de la información obtenida, tanto en Piura como en Sullana.

\section{ANÁLISIS DE DATOS}

Para el proceso de análisis, iniciamos con una lista preliminardecódigos (enfoquede "TeoríaFundamentada"; o Grounded Theory) a fin de evitar el sesgo personal o la simplificación excesiva, esperábamos que a partir de la narración de experiencias de los participantes surgieran las categorías que finalmente representaron los núcleos de sentido claves, que nos permitieron ampliar el libro de códigos.

La lista de códigos preliminar incluyó: uso de antirretrovirales, transmisión de $\mathrm{VIH}$, no uso de preservativo en las relaciones coitales, momento de colocación del preservativo, número y tipo de pareja sexual (estable u ocasional), carga viral indetectable, autoerotismo, infecciones de transmisión sexual, tipo de coito (oral, vaginal y anal), estilos de vida y reinfección por VIH.

Con ayuda del software ATLAS.ti versión 5.0, se realizó la segmentación del corpus discursivo, extrayendo los fragmentos que contenían los códigos para definir las unidades básicas, contrastando y comparando las distintas opiniones, según estratos. Luego, los fragmentos extraídos fueron agrupados en dos unidades temáticas: creencias sobre uso de antirretrovirales y transmisión del $\mathrm{VIH}, \mathrm{y}$ creencias sobre tener comportamientos sexuales de riesgo después de iniciar TARGA, se incluye aquellas sobre la experiencia de tener más de una pareja sexual en los últimos seis meses, no usar preservativo en dichas relaciones sexuales, y tipo coito practicado (oral, anal o vaginal).

\section{RESULTADOS}

\section{CREENCIAS SOBRE USO DE ANTIRRETROVIRALES Y TRANSMISIÓN DEL VIH}

Los varones y mujeres participantes de los grupos focales y entrevistas en profundidad, afirman que luego de iniciar la toma de antirretrovirales, experimentaron una notable mejoría en su salud. Esto es debido a la creencia de que los medicamentos producen un "adormecimiento del virus", con la consiguiente disminución de las molestias ocasionadas por infecciones oportunistas, que les permite retornar a sus actividades cotidianas

... Yo... estaba bastante mal, pero al tomar los medicamentos comencé a recuperarme, casi 
he vuelto a ser el mismo de antes, gracias a los medicamentos.

Varón, GF Sullana

Ahhh sí, yo también me he preguntado... y me informé que actúan [los antirretrovirales] manteniendo al virus dormido pues, es como se puede decir que el virus ya se ha dormido y ya no nos afecta para mal, las pastillas que tomamos lo hacen dormir y ya pues, ya no nos afecta... y ya estamos como antes.

Varón, GF Sullana.

Respecto a la posibilidad de transmisión del "virus adormecido", varones y mujeres que lleven menos de una año en tratamiento expresaron que en las relaciones sexuales sí se puede transmitir el virus, pero éste, al encontrase en situación de "adormecimiento" no va a ocasionar daño en la persona sana, salvo que el virus se "despierte", lo cual es variable en tiempo y dependerá del estilo de vida de la persona a quien se transmitió el virus.

Para mí, si pasa el virus al tener sexo con otra... pero no le hace daño... va a seguir sana como se dice ¡como si nada!, salvo que el virus se despierte.

Mod. ¿Cuánto tiempo tarda para despertarse el virus, o qué circunstancias permiten que el virus se despierte?

Eso más que todo depende de la persona, si se cuida y no es promiscua, nada le va a pasar; depende de su alimentación, de su ritmo de vida... a veces nunca se despierta, porque yo he tenido relaciones con... una vez pasó, era un tipo zanahoria como se dice... hasta ahora, la última vez que lo vi está bien, andaba sano... Allí por ejemplo seguirá adormecido el virus, y nada le hace.

Mujer, GF Sullana

Participantes mujeres, que llevan menos de un año recibiendo antirretrovirales, afirmaron que cuando escucharon el término "carga viral indetectable", usado frecuentemente por los profesionales de salud, lo vincularon con la creencia de "haberse curado de la infección".

Cuando el doctor me dijo... como se llama, con esta... o sea muy... y estaba "indetectable" mi virus, iyo me sentí muy alegre!...

Mod: ¿Y por qué se sintió alegre cuando le dijeron que estaba indetectable?

Porque yo pensé... cuando me dijeron "estas indetectable" yo creía que ya no tenía el VIH, que ya había pasado la pesadilla... que había actuado bien el medicamento, ya estaba muy contenta, muy feliz...

Mujer, GF Piura

\section{COMPORTAMIENTOS SEXUALES POST DIAGNÓSTICO POSITIVO PARA VIH}

Algunos varones, desde su experiencia personal o por lo que refieren sus pares, manifiestan que luego de enterarse del diagnóstico positivo para $\mathrm{VIH}$ no adoptaron medidas de protección en sus relaciones sexuales, por el contrario, afirmaron que comenzaron a tener relaciones coitales en mayor número y frecuencia, con diferente tipo de pareja, con la finalidad de "vengar" su situación personal de haber sido infectado/a "inocentemente con VIH".

Me siento culpable porque a veces yo si lo he hecho sin preservativo, no sabía lo que hacía, lo hacía como te digo...... No me interesaba nada, yo decía si a mi me fregaron también tengo que fregar a alguien y por eso tenia sexo sin condón, pero yo sé que hacía muy mal. Lo tenia con mujeres, con hombres y normal... la cosa era que yo quería contagiar a todos los que se pueda, porque así lo hicieron conmigo... yo así pensaba en esos momentos, claro que ahora ya cambié, ahora ya no Varón Bisexual, GF Sullana

Es que en el primer momento que tú te enteras... no crees, es lo que yo decía "Es imposible que yo tenga esta enfermedad"... pero luego pensando bien pues, pues nunca me había detenido a pensar que por mis conductas me iba a contagiar... luego viene un momento como se dice... yo pensaba "Si me contagiaron, yo también voy a contagiar... Así como me lo han hecho a mí" y bueno si tuve varias parejas, algunas eran conocidas, pero casi la mayoría eran desconocidas. Varón, EP 30 años

El tiempo que transcurre desde el momento del diagnóstico hasta cuando acuden al establecimiento de salud para recibir terapia antirretroviral es variable, pero generalmente mayor a un año, periodo en el cual el comportamiento sexual se ha caracterizado por un alto intercambio de parejas con las cuales no se han tomado medidas de protección, conforme se describió anteriormente.

Al profundizar cómo se desarrolla la orientación y consejería para dar el diagnóstico positivo, se encuentra que ésta consiste en una sola sesión de 30 minutos aproximadamente, en la cual no es posible concientizar a las personas de su condición de seropositividad y la importancia de establecer mecanismos de protección personal y hacia los demás, a fin de romper la cadena de transmisión

También encontramos que con el transcurrir del tiempo, tanto varones como mujeres experimentaron disminución 
de la frecuencia del coito debido al deterioro de su salud física por las infecciones oportunistas, pero luego de iniciar la terapia antirretroviral mejoran notablemente su salud con el consiguiente reinicio de su actividad sexual

Cuando uno viene al TARGA viene mal, muy mal... luego ya los medicamentos te levantan, te dan mejoría y ya algunos... y también las mujeres y hombres, al sentirse mejor otra vez vuelven... como se dice vuelven a las andanzas (...) claro otra vez tiene sexo así no más [sin usar preservativo] Mujer, EP 33 años

\section{ELRIESGOENLOSCOMPORTAMIENTOSSEXUALES, LUEGO DE INICIAR TARGA}

Los comportamientos sexuales de riesgo en los que se involucran las personas que viven con $\mathrm{VIH}$, luego de iniciar TARGA, tuvieron como eje central de análisis el tipo de pareja sexual (estable u ocasional), tipo de coito practicado (oral, vaginal o anal) y uso correcto del preservativo en sus coitos.

Respecto al tipo de pareja sexual, existen concepciones diferenciadas para tener coito con pareja ocasional o estable. En el caso de tratarse de pareja ocasional, algunos varones manifestaron que no adoptan medidas de protección, porque no existe un vínculo afectivo con ellas/os y porque ya no van a frecuentar a dicha pareja y ésta no va a reclamarle nada si resultare infectada.

Otros varones enfatizan que las trabajadoras sexuales saben cómo cuidarse para evitar la transmisión de la infección, por lo tanto, cuando se relacionan con ellas no adoptan medidas de protección.

Pero también depende con la persona con quien lo hagas, si es tu pareja hay que cuidarla, pero si es la prostituta, ellas saben como hacer... Varón, GF Sullana

Mientras que cuando se tiene coito con parejas conocidas o estables, consideran especiales cuidados para no transmitirle la infección.

A mí también me pasó con alguien, de verdad que me enamoré de esa persona, pero decidí cortar, porque no quería llegar más allá, porque sabía que llegaría a tener sexo o sea... ya era algo delicado. Porque una cosa es tener una pareja ocasional... alli no hay tanto problema porque sabes que ya no la vas a ver, no la vas a frecuentar... pero con alguien que te enamoras, es ya tener una pareja sentimental, una pareja estable y allí no vale malograrla, no vale arriesgarla...

Varón, GF Sullana
Sobre el tipo de coito practicado, algunos informantes refieren que tanto varones como mujeres y muchos de sus pares, aún mantienen comportamientos sexuales de riesgo (prácticas sexuales anales, orales y vaginales insertivas o receptivas desprotegidas).

...Pero a veces uno no se puede aguantar no tener por atrás [coito anal insertivo], yo me pongo de acuerdo con mi compañera o compañero de turno $y$ de vez en cuando tengo [coito anal insertivo], o sea no es igual porque hay resistencia pero al final los termino convenciendo

Mod: $Y$ en esas veces que logra convencer a su pareja, ¿usa medidas de proteccion?

Depende, depende si la conozco... a veces, le confieso que no me puse nada... ellos tampoco me exigían

Varón Bisexual, GF Piura.

No se encontró discursos vinculados con la definición más amplia de la sexualidad que abarque la exploración del cuerpo como un gran espacio para brindar y recibir placer.

O sea que le digo... cuando una sólo lo hace con caricias, así como que te acaricien nada más, te deja con las ganas... mejor es sentir a tu pareja, que te penetre... así es más rico (risas) yo creo que es como si te masturbaras porque te quedas a mitad de camino... yo no quiero eso.

Mujer, EP 33 años

Esta forma como se concibe y se practica la sexualidad hace que varones, pero especialmente mujeres, cuestionen y rechacen la masturbación, que uno de los participantes más jóvenes afirmaba practicar, quien refirió que la masturbación es una alternativa para evitar transmitir la infección de VIH. Otros participantes varones manifestaron que la masturbación los hace sentir menos "peligrosos" para los otros, mientras que en el caso de las mujeres es rechazada tajantemente, por las creencias y prejuicios construidos socialmente, hubo mucha reserva por parte de ellas para tratar este tema.

...Para mí la masturbación creo que es mucho mejor porque no te contagias y no contagias a nadie... yo me masturbo cuando quiera $y$ donde yo quiero y lo mejor es que ya no estoy pensando... “¿Y si voy a contagiar a alguna?”... eso ya no pasa en mi... ya no tengo miedo que me contagien nuevamente... para eso mejor me masturbo y me siento mejor... Varón, GF Piura.

En lo referente al uso del preservativo, manifiestan que es desagradable; varones y mujeres afirman que 
algunas personas que tienen la infección no usan preservativo en forma consistente en sus relaciones sexuales a pesar que reconocen las posibilidades de transmisión de la infección. Algunos mencionaron el uso del preservativo como una experiencia esporádica y ocasional. Detallando las siguientes razones, por las cuales no los usan:

Porque no siempre tienen un preservativo disponible. Yo he escuchado en otras personas [con VIH] que han estado en tragos y han estado con otra pareja... y no han podido cuidarse porque no tenían a mano el preservativo... seguramente que las han contagiado

HSH, GF Sullana.

Porque lo consideran innecesario cuando su pareja también tiene VIH

Por eso... yo decía si ya tenemos los dos SIDA, para que necesitamos el condón... mi mujer también decía lo mismo y así teníamos sexo... Varón, GF Sullana.

Porque causa incomodidad en el coito ... No es lo mismo, sientes como un poco de dolor... en mi caso se siente dolor, ardencia(sic), es por el preservativo... cuando ya se seca el lubricante, se seca y te causa dolor, y ya no es lo mismo ¿no? HSH, GF Piura.

Por creencias que el uso del preservativo interfieren con el placer sexual

...En mi caso yo soy de las personas que no gusta tener relaciones con preservativo... yo les decía muy claro, isi te pones preservativo yo no tengo relaciones contigo!, yo soy así, hasta ahora lo detesto, bueno casi nunca lo he usado porque me parece desagradable, no siento nada porque es como una barrera

Mujer, GF Sullana

\section{DISCUSIÓN}

Los resultados de este estudio, indican que las personas que viven con $\mathrm{VIH}$ y reciben TARGA tienen comportamientos sexuales de riesgo. Esto está de acuerdo con lo encontrado en estudios epidemiológicos de naturaleza cuantitativos recientemente publicados que afirman, que el inicio de la era TARGA está relacionada con la continuación o incremento de comportamientos sexuales de riesgo entre hombres homo- y bisexuales, así como con brotes de sífilis y gonorrea en Norte América y Europa ${ }^{(2,4,11)}$.

Dos razones podrían explicar por qué las personas que viven con $\mathrm{VIH}$ y que reciben TARGA tienen comportamientos sexuales de riesgo, en primer lugar existe la creencia de queal producirse el "adormecimiento" del virus por acción de los antirretrovirales, no hay peligro si el virus de VIH "adormecido" se trasmite a una persona sana, en todo caso dependerá del estilo de vida de esta persona para que desarrolle la infección. En segundo lugar, hay la creencia que cuando el personal de salud les comunica que tienen carga viral indetectable, consideran que han sido curados de la infección.

Este hallazgo se apoya en los estudios de Dukers quien concluye que lo que realmente influye en la práctica sexual no segura, son las mejoras virológicas e inmunológicas proporcionadas por los medicamentos antirretrovirales y no su administración en sí (13).

Respecto al tipo de pareja sexual, se encontró que algunas personas que adoptan medidas de protección dependiendo del tipo de pareja con la que tienen coito, cuando se trata de parejas ocasionales refieren que no usan medidas de protección, mientras que cuando se trata de una pareja estable, se despliegan muchos cuidados para evitar transmitir la infección. Otros estudios muestran la falta de protección y el aumento de relaciones sexuales de riesgo tanto en parejas estables como en las ocasionales ${ }^{(9)}$. En nuestros hallazgos se encuentra que la razón principal para no protegerse depende básicamente de que no hay un vínculo sentimental con la pareja ocasional y que ésta no va a reclamarle posteriormente si resultare infectada.

El preservativo es considerado desagradable e incómodo para las relaciones sexuales, esto concuerda con estudios realizados en personas que no tienen $\mathrm{VIH}^{(14-16)}$, porque interfiere con el placer sexual. Un estudio reciente evidencia que el uso del preservativo en la última relación sexual fue del $37 \%$ en personas de 20 a 24 años (población general) y $32 \%$ en personas privadas de la libertad ${ }^{(17)}$.

En el caso de las personas afectadas por VIH esta actitud es preocupante porque no están asumiendo ninguna protección ante las reinfecciones, ni para la transmisión del virus a sus parejas serodiscordantes.

En conclusión, las personas que viven con $\mathrm{VIH}$ y reciben TARGA parecen tener comportamientos sexuales de riesgo y, con ello, estarían facilitando la transmisión del virus a sus parejas serodiscordantes e incrementando el número de personas infectadas con VIH en nuestro medio.

Hasta la actualidad, las actividades de prevención para el VIH a nivel nacional y mundial, se han dirigido específicamente hacia las personas que se supone no están infectadas, para evitar su posterior infección; sin embargo, con estos resultados, es evidente que la 
disminución de la transmisión del VIH y otras ITS también requiere de un trabajo de prevención secundaria sobre las personas que ya están infectadas, considerando un abordaje integral de la sexualidad.

Las intervenciones en las personas que reciben diagnóstico positivo para $\mathrm{VIH}$ requiere mucho más de una sesión de consejería, es importante desarrollar un programa educativo que contemple aspectos dirigidos a concientizar sobre la importancia de adoptar medidas de protección ya que se considera que el periodo postinfección es el más infeccioso por contacto sexual ${ }^{(18)}$. Más aun cuando se ha demostrado que con el inicio de TARGA mejoran las condiciones de salud incluyendo la salud sexual, y con ello tener comportamientos sexuales de riesgo, con la consecuente creación de una nueva amenaza para la salud pública a través de la transmisión de virus resistentes a los tratamientos actuales, situación que viene ocurriendo con otras enfermedades como la tuberculosis.

\section{AGRADECIMIENTOS}

A todas las personas que participaron del estudio, por sus valiosas respuestas en temas tan personales e íntimos. Así mismo agradecemos al personal de salud, por el apoyo brindado durante la recolección de información y por permitirnos ingresar a sus espacios de atención. Agradecemos al Dr. César Munayco y a la Lic. Jeannette Avila por su apoyo durante todo el proceso de la investigación.

\section{Fuente de Financiamiento}

Dirección General de Epidemiología, Ministerio de Salud de Perú.

\section{Conflictos de Interés}

Los autores declaran no tener conflictos de interés en la ejecución y publicación de esta investigación.

\section{REFERENCIAS BIBLIOGRÁFICAS}

1. UNAIDS. AIDS Epidemic Update, 2009. Geneva:UNAIDS, 2009.

2. Royce RA, Seña A, Cates WJJ, Cohen MS. Sexual transmission of HIV. N Engl J Med. 1997; 336(15): 1072-8.

3. Katz MH, Schwarcz SK, Kellogg TA, Klausner JD, Dilley JW, Gibson S, et al. Impact of Highly Active Antirretroviral Treatment on HIV Seroincidence Among Men Have Sex With Men: San Francisco. Am J Public Health. 2002; 92: 388-94.

4. Vall M. La reemergencia de las infecciones de transmisión sexual. Enf Emerg. 2004; 6(2): 65-7.

5. Rietmeijer CA, Patnaik JL, Judson FN, Douglas JM Jr. Increases in gonorrhea and sexual risk behaviors among men who have sex with men: a 12-year trend analysis at the Denver Metro Health Clinic. Sex Transm Dis. 2003; 30(7): 562-67.

6. Desquilbet L, Deveau C, Goujard C, Hubert JB, Derouineau J, Meyer L; PRIMO Cohort Study Group. Increase in at-risk sexual behaviour among HIV-1-infected patients followed in the French PRIMO cohort. AIDS. 2002; 16(17): 2329-33.
7. Remien R, Halkitis PN, O'Leary A, Wolitski RJ, Gómez CA. Risk perception and sexual risk behaviors among HIV-Positive men on antiretroviral therapy. AIDS Behavior. 2005; 9(2): 167-76.

8. Wilson TE, Gore M, Greenblatt R, Cohen M, Minkoff H, Silver $\mathbf{S}$ et al. Changes in Sexual Behavior Among HIVInfected Women After Initiation of HAART. Am J Public Health. 2004; 94(7): 1141-46.

9. Stolte G, Dukers NH, de Wit JB, Fennema H, Coutinho RA. Informe resumen de la situación en Amsterdam: aumento de las enfermedades de transmisión sexual y de los comportamientos sexuales de riesgo en hombres homosexuales, relacionados con la introducción de los nuevos tratamientos anti-VIH. Euro Surveill. 2002; 7(2): 19-22.

10. Folch C, Casabona J, Muñoz R, Zaragoza K. Evolución de la prevalencia de infección por el VIH y de las conductas de riesgo en varones homo/bisexuales. Gac Sanit. 2005; 19(4): 294-301.

11. Do AN, Hanson DL, Dworkin MS, Jones JL; Adult and Adolescent Spectrum of HIV Disease Project. Risk factors for and trends in gonorrhea incidence among persons infected with HIV in the United States. AIDS. 2001; 15(9): 1149-55.

12. Crepaz N, Hart TA, Marks G. Highly active antiretroviral therapy and sexual risk behavior: a meta-analytic review. JAMA. 2004; 292(2): 224-36.

13. Dukers NH, Goudsmit J, de Wit JB, Prins M, Weverling GJ, Coutinho RA. Sexual risk behaviour relates to the virological and immunological improvements during highly active antirretroviral therapy in HIV-1 infection. AIDS. 2001; 15(3): 369-78.

14. Arias R, Aramburú C. "Uno empieza a alucinar..." Percepciones de los jóvenes sobre sexualidad, embarazo y acceso a los servicios de salud: Lima, Cusco, Iquitos, 1997. Lima: Redess Jovenes/Fundación Summit; 1999.

15. Palomino N, Ramos M, Valverde R, Vásquez E. Entre el placer y la obligación. Derechos sexuales y derechos reproductivos de mujeres y varones en Huamanga y Lima. Lima: FASPA-UPCH / Population Concern; 2003.

16. Cáceres $C$, Salazar $X$, Rosasaco AM, Fernandez DP. Ser hombre en el Perú de Hoy. Una mirada a la salud sexual desde la infidelidad, la violencia y la homofobia. Lima: Redess Jóvenes; 2002.

17. CARE Perú, Universidad Peruana Cayetano Heredia. Estudio de medición de línea de base de los objetivos 1-4 del componente VIH del Programa: Cerrando brechas hacia el logro de los objetivos del milenio en TBC y VIH/SIDA en el Perú. Propuesta con enfoque de descentralización multisectorial participativa (Informe Final) Lima: CARE, UPCH; 2007.

18. Pao D, Fisher M, Hué S, Dean G, Murphy G, Cane PA et al. Transmission of $\mathrm{VIH}-1$ during primary infection: relationship to sexual risk and sexually transmited infections. AIDS. 2005; 19(1): 85-90.

Correspondencia: José P. Juárez Vilchez.

Domicilio: Calle Santa Elena 114 (Por puerta lateral de Colegio Las Capullanas). Sullana, Perú.

Teléfonos: 969829454 / (073) 501424

Correo electrónico: pymjuarez@hotmail.com 